\title{
Comparative analysis of two methods for synthesis of fullerenes at different helium pressures
}

\author{
Alexander I. Dudnik ${ }^{\mathrm{a}, \mathrm{b}}$, Irina V. Osipova ${ }^{\mathrm{a}}$, Nikita S. Nikolaev ${ }^{\mathrm{a}, \mathrm{b}}$, Grigory N. Churilov ${ }^{\mathrm{a}, \mathrm{b}}$ \\ ${ }^{a}$ Kirensky Institute of Physics, Federal Research Center KSC SB RAS, Krasnoyarsk, Russia \\ ${ }^{\mathrm{b}}$ Siberian Federal University, Krasnoyarsk, Russia
}

The results of the effect of helium pressure in the chamber on the amount and composition of the produced fullerenes $\left(\mathrm{C}_{60}, \mathrm{C}_{70}\right.$, etc. $)$ synthesized in the arc plasma with graphite electrodes are presented. The findings obtained when the arc is powered by a direct (DC) and alternating (AC) currents of low frequency were compared in the same chamber with the electrodes located at the same angle to each other. These two methods are drastically different. The complete conversion of graphite into fullerene soot in AC occurs, but a part of the graphite is converted into a cathode deposit that does not contain fullerenes in DC, the relative amount of which increases when decreasing the helium pressure in the chamber. The highest fullerene content in fullerene soot of $10.2 \mathrm{wt} . \%$ is produced at a pressure of $127.5 \mathrm{kPa}$ in $\mathrm{AC}$ arc, but in $\mathrm{DC}$ arc, the highest content of fullerenes in fullerene soot of 8.3 wt. $\%$ is produced at a pressure of $33.3 \mathrm{kPa}$.

Keywords: fullerene synthesis, alternating current, direct current

\section{Introduction}

A method of fullerene soot (FS) production process described by W. Krätschmer et al. in a plasma of the direct current (DC) arc in a helium atmosphere at pressure of $13.3 \mathrm{kPa}$ [1] and its various modifications remains one of the most effective until recently [2-6]. At the beginning of the 90 s of the last century, there appeared many scientific publications on new methods for producing fullerenes and on the influence of various parameters on their formation [7-11]. Interest was to find out the most commercially viable synthesis method on the one hand, and to understand the formation mechanisms of closed spheroidal carbon structures, i.e. fullerenes, on the other hand. At present, the fundamental interest in fullerene formation processes is much higher than the commercial one.

The efficiency of fullerene formation depends on many parameters: pressure and purity of helium, current magnitude, chemical composition of electrodes, and their size and location geometry. Even small changes in the parameters do affect the efficiency of fullerene formation both for synthesis 
in plasma of the DC arc and for alternating current (AC). As mentioned above, it is inadmissible to compare the results obtained using different set-ups.

An analysis of the literature showed that a comparison of two methods for the fullerene synthesis in DC and AC using the same set-up and under the same conditions has not been carried out yet. Comparison of these two methods is of current interest, both from a fundamental and an applied point of view. The general patterns of plasma-chemical synthesis of fullerenes will also correspond to the plasma-chemical synthesis of any nanodispersed substances such as nanotubes, particles with corecarbon shell structure, metal carbides, etc. Currently, helium pressure is well known to be the main parameter which the amount and composition of the produced fullerenes is depended on [12-15]. Accordingly, the results and parameters of the fullerene synthesis in arc discharge plasma of DC and $\mathrm{AC}$ (frequency $66 \mathrm{kHz}$ ) carried out at different chamber helium pressures in the range of 13.3-353 kPa are presented in the given work.

\section{Experimental procedures}

The synthesis of fullerenes was performed on the set-up we developed, Figure 1 [16]. The chamber diameter is $24 \mathrm{~cm}$, the height of the chamber body is $30 \mathrm{~cm}$. To maintain the given arc current, the set up provides an automatic electrode feed, with the current magnitude matching the certain electrode gap. The syntheses were performed on two electrodes located at an angle of $74^{\circ}$ to each other. Graphite rods for spectral analysis with a diameter of $6 \mathrm{~mm}$ were used as electrodes. The rods were preannealed at a pressure of $7 \mathrm{mPa}$ under the temperature of $1500{ }^{\circ} \mathrm{C}$ for $30 \mathrm{~min}$. Helium (grade - A, purity - 99.995\%) was fed through a nitrogen trap (3) at a rate of $6 \mathrm{1} / \mathrm{min}$. The studied pressures ranged from 13.3 to $353 \mathrm{kPa}$. The DC circuit consisted of a three-phase autotransformer, step-down transformer, diode rectifier and choke, Figure 1. The current form in the load circuit was detected with an oscilloscope connected to an ammeter shunt. A power amplifier working in the frequency range $40-120 \mathrm{kHz}$ was used for synthesis of fullerenes in low frequency AC. Synthesis was conducted at a frequency of $66 \mathrm{kHz}$. The current form in the power amplifier circuit was also detected using an oscilloscope on a current transformer. The current forms of DC and AC arc are shown in the oscillogram of Figure 2. The arc current for all syntheses was $130 \pm 10 \mathrm{~A}$. 


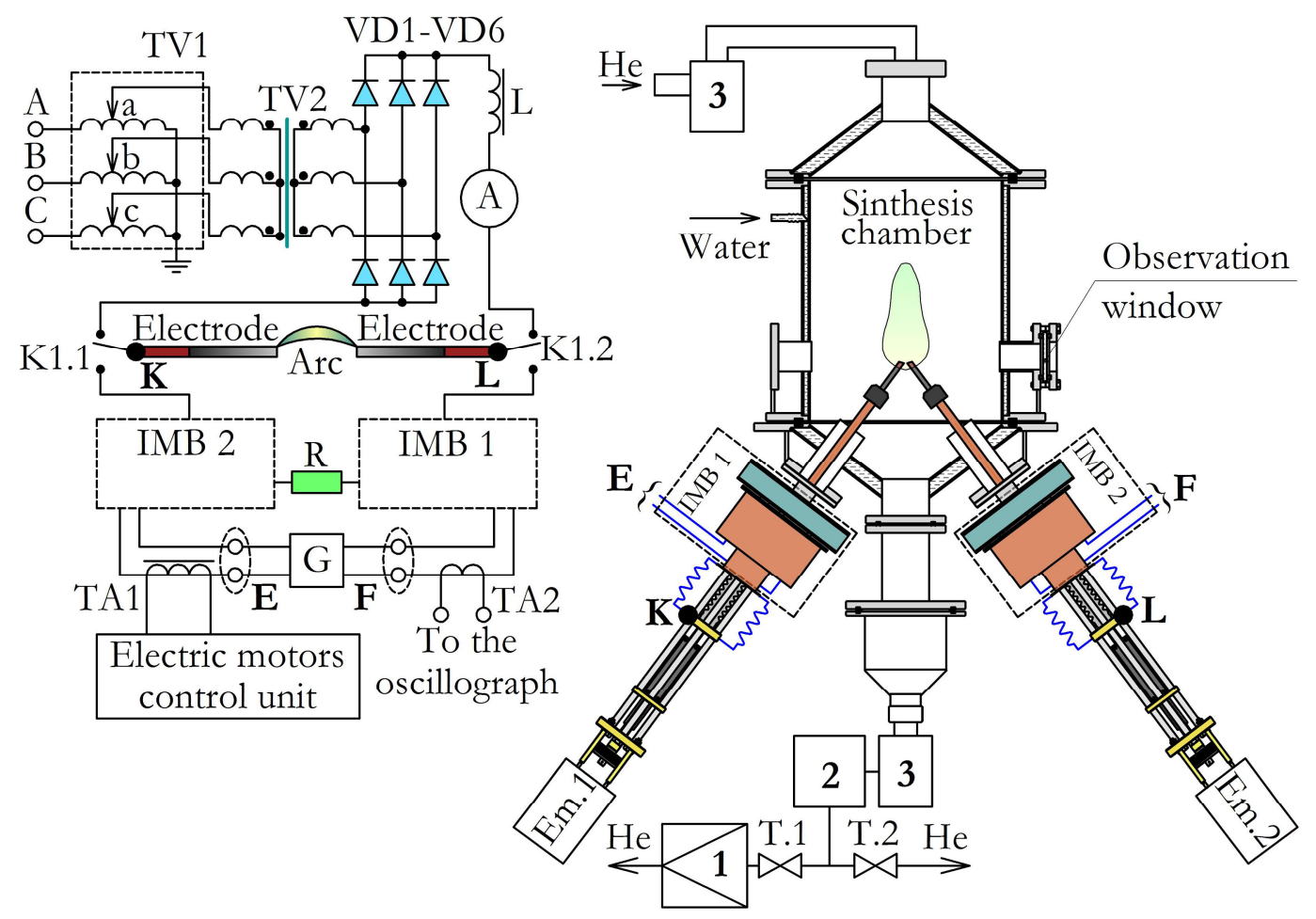

Figure 1. Functional diagram of the set-up for the synthesis of fullerenes.

Em. 1 and Em.2 - electrode feed motors; IMB1 and IMB2 - impedance match block of the generator and the load; TA1, TA2 - current transformers; G - power amplifier; K, L - points of the power supply to the load; E, F - points of the power amplifier; T.1 and T.2 - ball valves;

1 - forepump; 2 - device for maintaining a given chamber pressure; 3 - nitrogen trap.

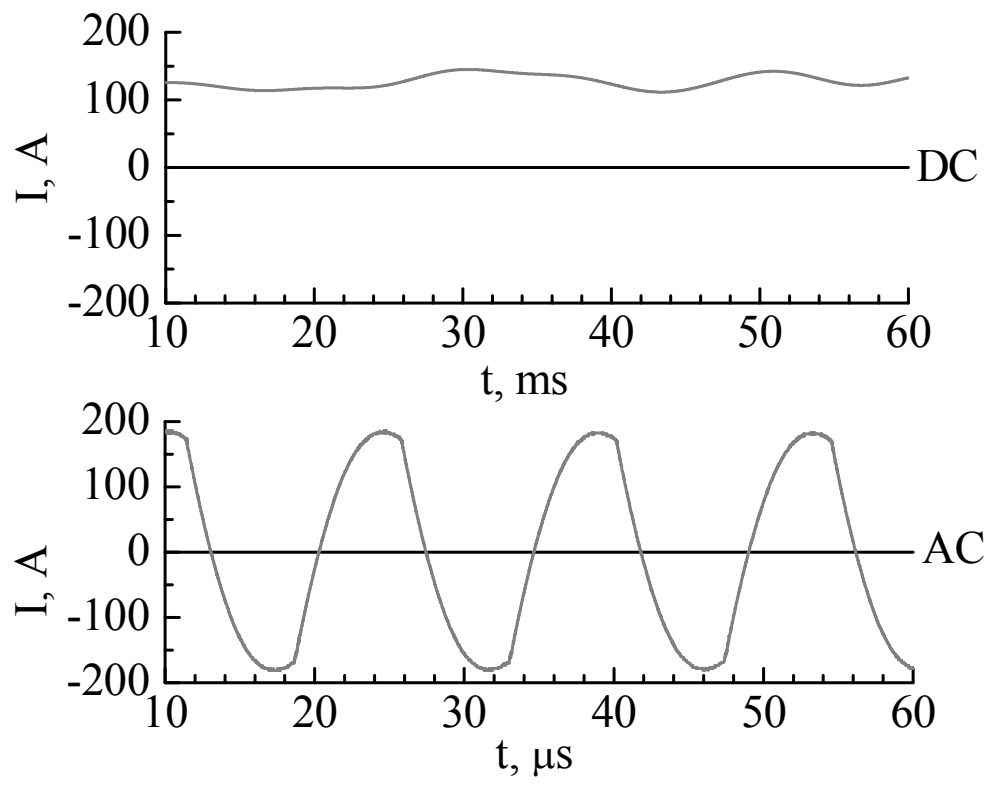

Figure 2. Oscillograms of the arc current at a pressure of $33.3 \mathrm{kPa}$

The fraction of cathode deposit (CD) produced during DC synthesis was determined as the $\mathrm{CD} /(\mathrm{CD}+\mathrm{FS})$ ratio, with the erosion rate of the electrodes given as the ratio of the mass of evaporated 
part of the graphite rod to the synthesis time. Fullerenes were separated from FS with benzene in a Soxhlet apparatus. The fullerene content was measured by the weight method, as the ratio of the weight of fullerene extract (FE) to the weight of the used FS. The error was determined by three syntheses for each pressure being no more than $0.8 \mathrm{wt} . \%$. The isolated fullerenes were redissolved in toluene and analyzed by high performance liquid chromatography (HPLC) using an Agilent Technologies 1200 Series chromatograph equipped with a Cosmosil Buckyprep-M (10 mm $\times 250 \mathrm{~mm})$ column. The chromatograms were detected at $324 \mathrm{~nm}$. The nature of fullerene solubility is cluster type, the solubility and absorption coefficients of the individual fullerenes in toluene haven 't currently been identified. Accordingly, solutions of the same concentration were prepared using the same weighed quantity of FE for both synthesis methods and analyzed by HPLC. The relative content of individual fullerenes $\mathrm{C}_{\mathrm{n}}\left(\mathrm{n}=60,70,76,78,80,84\right.$, etc.) was determined as the ratio $S_{\mathrm{Cn}} / S_{\text {Fullerenes, }}$ where $S_{\mathrm{Cn}}$ is the peak area of individual fullerene in the FE chromatogram, and $S_{\text {Fullerenes }}$ is the total area of all detected peaks. A comparison of individual fullerene formation efficiency in the plasma of AC arc with respect to that in the plasma of DC arc was presented as the $C_{n}(A C) / C_{n}(D C)$ ratio. Where, $C_{n}(A C)$ is the relative content of individual fullerene in FS obtained in the plasma of $\mathrm{AC}$ arc, and $\mathrm{C}_{\mathrm{n}}(\mathrm{DC})$ is similar for DC.

\section{Results and discussion}

In course of fullerene synthesis in DC, the conversion of graphite to FS is significantly reduced due to the $\mathrm{CD}$ formation, Figure 3a. The synthesis of fullerenes in an arc discharge of AC allows one to avoid the $\mathrm{CD}$ formation, with the transformation of graphite into FS occurring with complete conversion without loss, Figure 3b. The dependence of the produced CD amount on the helium pressure is shown in Figure 4. When increasing pressure during DC synthesis, the CD fraction is seen to decrease. The maximum CD content (47 wt.\%) corresponds to the maximum amount of fullerenes in FS (8.3 wt.\%) at a pressure of $33.3 \mathrm{kPa}$. In addition, high cathode erosion occurs at a pressure of $225.5 \mathrm{kPa}$ and above. For instance, the cathode loses as much as $32 \mathrm{wt} . \%$ at a pressure of $353 \mathrm{kPa}$. 


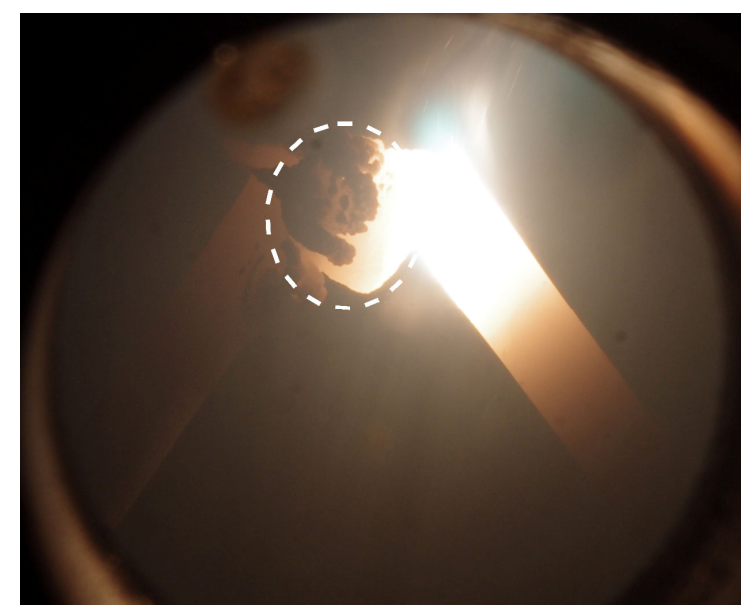

(a)

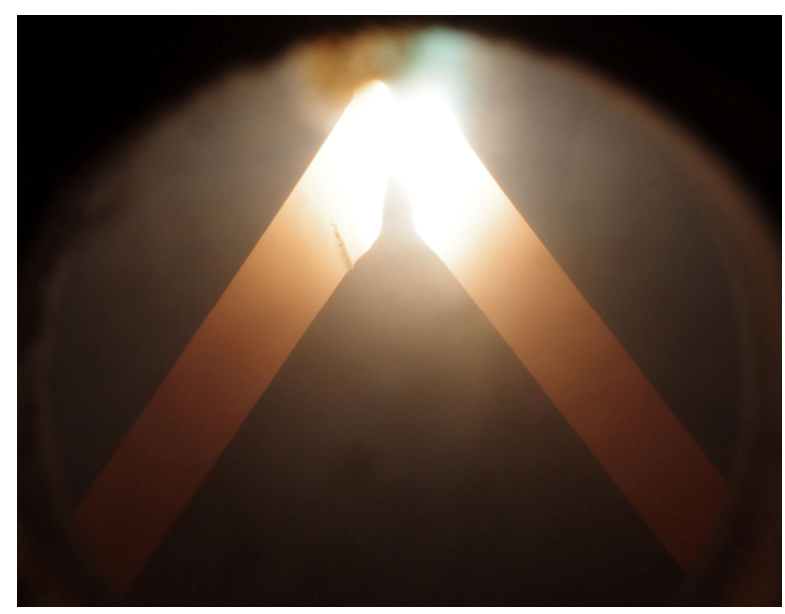

(b)

Figure 3. Photographs of graphite electrodes at a pressure of $33.3 \mathrm{kPa}$ : (a) DC (the circled area is CD formation), (b) AC.

The erosion patterns of the rods during DC and AC discharge power supply are also different. Anode erosion occurs in DC, both electrodes erode in AC. The electrode area with the most severe erosion has the highest luminosity (Figure 3), with the luminescence intensity of the areas closest to the discharge in DC being higher than in AC. Observing two discharge rates between graphite electrodes, AC discharge is seen to have the diffuse nature, while it is more constricted in DC. The difference of plasma formation process in AC and DC is due to the difference of the nature of current flow. In the former case, the current is equal to zero twice over the period, and in the latter case it remains constant throughout the discharge burns, Figure 2. In AC, there is a frequent transient, which ensures the diffuse nature of the discharge even at high pressure, up to $353 \mathrm{kPa}$.

The study results of the fullerene content in FS, the electrode erosion rate, and also the rate of $\mathrm{CD}$ formation as a function of the helium pressure in the chamber for DC and AC are shown in Figure 4. For DC, the significant increase in electrode erosion rate is observed with increasing pressure, which reaches $47 \mathrm{mg} / \mathrm{s}$ at a pressure of $353 \mathrm{kPa}$. For AC, the erosion rate also increases with increasing pressure and reaches $18 \mathrm{mg} / \mathrm{s}$ at a pressure of $353 \mathrm{kPa}$. The fullerene content in FS substantially depends on the chamber pressure and, in DC, reaches $8.3 \mathrm{wt} \%$ at a pressure of $33.3 \mathrm{kPa}$, Figure 4a. The second maximum of $6.5 \mathrm{wt} . \%$ corresponds to a pressure of $82.6 \mathrm{kPa}$. Thus, for the efficient synthesis of fullerenes in DC, a decreased helium pressure in the chamber, according to the published data [14], has to be used.

In $\mathrm{AC}$, the fullerene content in FS is characterized by two distinct maxima, at pressures below and above atmospheric pressure, Figure $4 \mathrm{~b}$. The maxima of fullerene content in FS are $10.0 \mathrm{wt} . \%$ and $10.2 \mathrm{wt} . \%$ observed at helium pressures in the chamber of 50 and $127.5 \mathrm{kPa}$, respectively. 


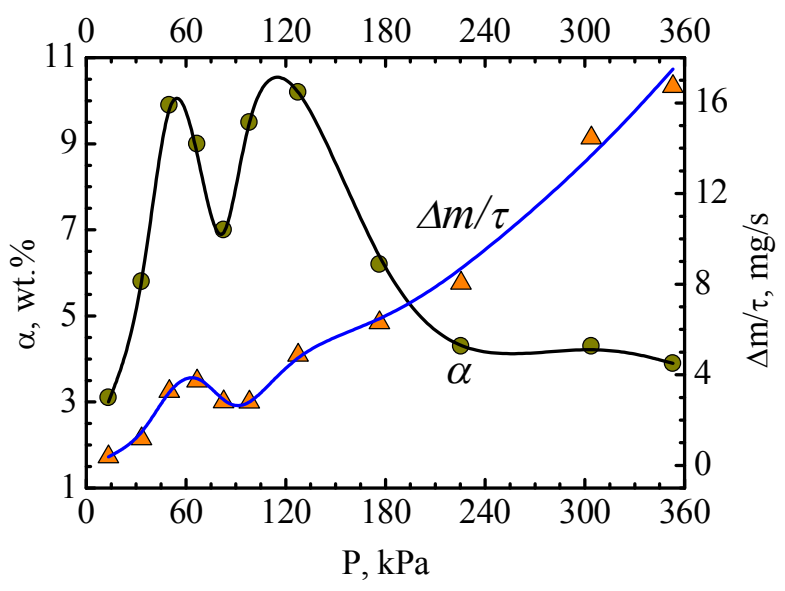

(a)

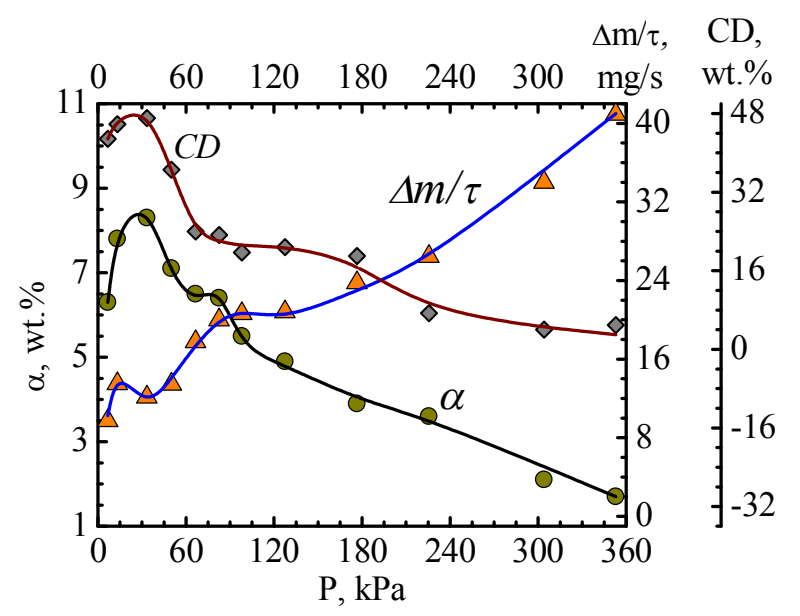

(b)

Figure 4. Dependence of fullerene content in FS $(\alpha)$, electrode erosion rate $(\Delta m / \tau)$ and CD fraction on helium pressure in the chamber: (a) DC, (b) AC.

The qualitative composition of FE obtained in DC does not differ from the composition of FE obtained in AC, however, some differences in the ratios of higher fullerenes are observed, Figure 5.

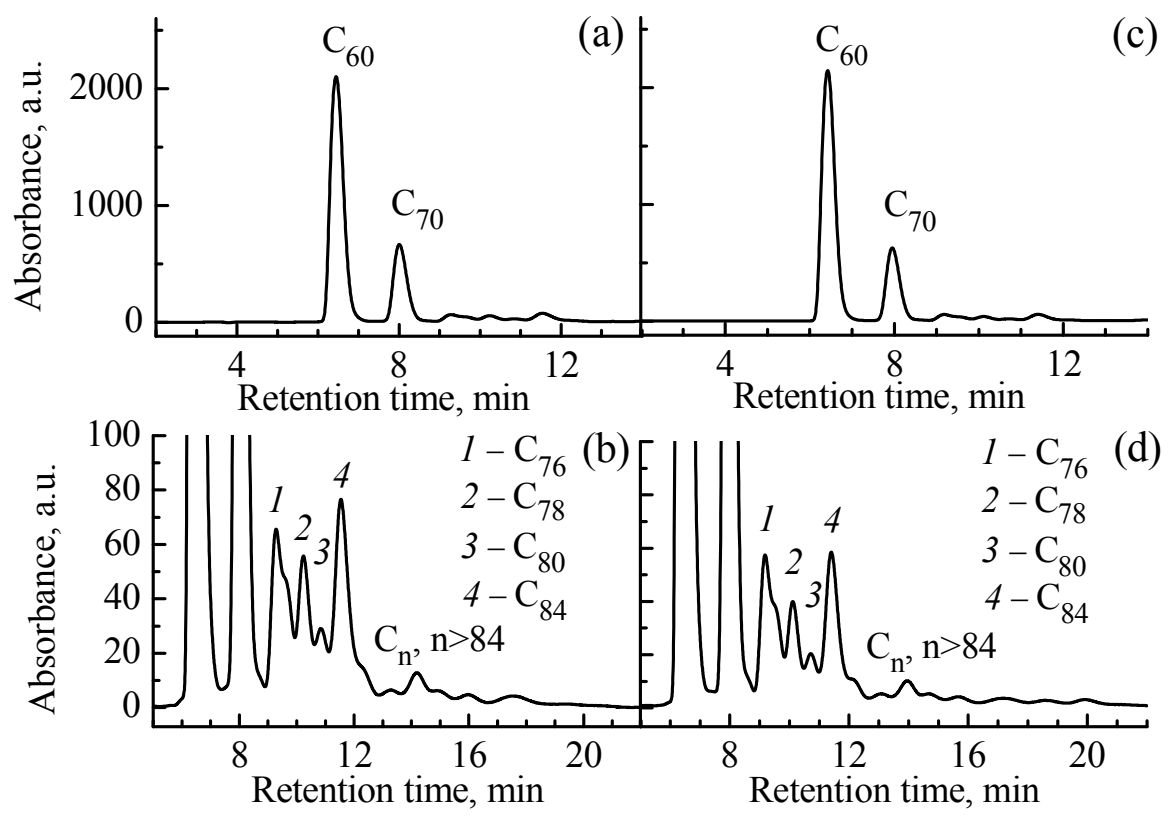

Figure 5. Chromatograms of FE obtained in DC (a, b) and AC (c, d) at a pressure of $127.5 \mathrm{kPa}$. Sample injection was $0.57 \mathrm{mg}$, eluent rate (toluene) was $5 \mathrm{~mL} / \mathrm{min}$.

In accordance with the method described above, the use of the relative content of individual fullerenes allows one not to take into account the particular value of the absorption coefficients and to evaluate the influence of the current type on the synthesis efficiency. Table 1 shows the data on five pressures: $13.3 \mathrm{kPa}$ is a pressure mostly indicated as the pressure wherein the fullerene content in FS is maximum during the synthesis in DC arc $[1,2] ; 33.3 \mathrm{kPa}$ is the first maximum of fullerene content in 
FS for the DC synthesis; $82.6 \mathrm{kPa}$ is the second maximum of fullerene content in FS for the DC synthesis; $127.5 \mathrm{kPa}$ corresponds to the second maximum of fullerene content in $\mathrm{FS}$ for the AC synthesis; $353 \mathrm{kPa}$ is considered as the limiting point in the studied range.

Table 1. The ratio of the peak area corresponding to the individual fullerene to the summed area of all peaks of the FE chromatogram.

\begin{tabular}{|c|c|c|c|c|c|c|c|c|c|c|}
\hline Current type & \multicolumn{5}{|c|}{ AC } & \multicolumn{5}{c|}{ DC } \\
\hline$P, \mathrm{kPa}$ & 13.3 & 33.3 & 82.6 & 127.5 & 353 & 13.3 & 33.3 & 82.6 & 127.5 & 353 \\
\hline$S_{\mathrm{C} 60} / S_{\text {Fullerenes, } \%}$ & 79.0 & 77.1 & 75.4 & 68.9 & 59.0 & 75.4 & 70.6 & 66.6 & 64.4 & 64.0 \\
\hline$S_{\mathrm{C} 70} / S_{\text {Fullerenes, } \%}$ & 18.9 & 19.1 & 19.8 & 20.9 & 24.6 & 17.8 & 18.6 & 21.5 & 21.6 & 21.9 \\
\hline$S_{\mathrm{Cn}} / S_{\text {Fullerenes }}(\mathrm{n}>70), \%$ & 2.1 & 3.8 & 4.2 & 10.2 & 16.4 & 6.8 & 10.8 & 11.9 & 14.0 & 14.1 \\
\hline$S_{\mathrm{C} 76} / S_{\text {Fullerenes, } \%}$ & 1.2 & 1.9 & 2.0 & 3.0 & 4.0 & 2.4 & 3.1 & 3.4 & 3.6 & 3.2 \\
\hline$S_{\mathrm{C} 78} / S_{\text {Fullerenes, } \%}$ & 0.1 & 0.3 & 0.4 & 1.5 & 2.9 & 0.9 & 1.5 & 1.9 & 2.3 & 2.1 \\
\hline$S_{\mathrm{C} 80} / S_{\text {Fullerenes, } \%}$ & 0.1 & 0.2 & 0.3 & 0.7 & 1.4 & 0.5 & 0.8 & 0.9 & 1.1 & 1.0 \\
\hline$S_{\mathrm{C} 84} / S_{\text {Fullerenes, } \%} \%$ & 0.6 & 1.2 & 1.2 & 3.1 & 5.8 & 1.9 & 2.9 & 3.6 & 4.4 & 4.6 \\
\hline$S_{\mathrm{Cn}} / S_{\text {Fullerenes }}(\mathrm{n}>84), \%$ & 0.1 & 0.2 & 0.3 & 1.9 & 2.3 & 1.1 & 2.5 & 2.1 & 2.6 & 3.2 \\
\hline
\end{tabular}

Since the summed area of all peaks in the chromatogram ( $\left.S_{\text {Fullerenes }}\right)$ corresponds to the same weight for all FE studied, it is possible to compare the formation efficiency of each individual fullerene in different types of discharge plasma. The relative content of individual fullerenes in FE obtained in the DC discharge and in the AC discharge can be seen in Table 1 to be different. To evaluate the synthesis efficiency in terms of graphite conversion to individual fullerene during DC and AC discharge power supply, the values of $C_{n}(A C) / C_{n}(D C)$ were calculated for all studied pressures, Table 2. To synthesize the higher fullerenes $C_{n}(n>70)$ at a pressure of $225.5 \mathrm{kPa}$ and lower, direct current is used more efficiently, and at pressures above $225.5 \mathrm{kPa}$ is AC as shown in Table 2. Both DC and $\mathrm{AC}$ can be used with the same efficiency in the entire studied pressure range $13.3-353 \mathrm{kPa}$ for the synthesis of $\mathrm{C}_{60}$ and $\mathrm{C}_{70}$ fullerenes.

Table 2. The efficiency of the formation of individual fullerenes in the AC and DC arc plasma.

\begin{tabular}{|c|c|c|c|c|c|c|c|c|c|c|c|}
\hline$P, \mathrm{kPa}$ & 13.3 & 33.3 & 50 & 66.6 & 82.6 & 98.1 & 127.5 & 176.5 & 225.5 & 304 & 353 \\
\hline $\mathrm{C}_{60}(\mathrm{AC}) / \mathrm{C}_{60}(\mathrm{DC})$ & 1.05 & 1.09 & 1.02 & 1.00 & 1.13 & 0.99 & 1.07 & 1.00 & 1.06 & 0.96 & 0.92 \\
\hline $\mathrm{C}_{70}(\mathrm{AC}) / \mathrm{C}_{70}(\mathrm{DC})$ & 1.06 & 1.03 & 0.98 & 0.88 & 0.92 & 0.95 & 0.97 & 0.97 & 0.93 & 1.09 & 1.12 \\
\hline $\mathrm{C}_{76}(\mathrm{AC}) / \mathrm{C}_{76}(\mathrm{DC})$ & 0.5 & 0.61 & 0.96 & 1.01 & 0.59 & 0.54 & 0.83 & 0.44 & 0.46 & 1.08 & 1.25 \\
\hline $\mathrm{C}_{84}(\mathrm{AC}) / \mathrm{C}_{84}(\mathrm{DC})$ & 0.32 & 0.41 & 0.74 & 1.20 & 0.33 & 0.52 & 0.70 & 0.44 & 0.37 & 1.04 & 1.26 \\
\hline
\end{tabular}




\section{Conclusions}

Thus, FE isolated from FS synthesized in DC and AC differ in composition. The presence of graphite losses due to the $\mathrm{CD}$ formation in DC syntheses and their absence during AC synthesis prove the advantage of the latter. Indeed, to obtain the same amount of fullerenes during the DC synthesis, it is necessary to use twice as much as graphite than during the AC synthesis. In this work, as in [15], the diffuse nature of the discharge was shown to be in accord with higher content of fullerenes in FS. As shown in the studies this can be achieved even at a pressure above atmospheric pressure $(127.5 \mathrm{kPa})$ in the $66 \mathrm{kHz} \mathrm{AC}$, and in DC only at pressures below atmospheric pressure ( $33.3 \mathrm{kPa}$ is best used).

\section{Acknowledgments}

The reported study was funded by RFBR according to the research project № 18-32-20011.

\section{Conflict of interest}

The authors declare that they have no conflict of interest.

\section{References}

1. Krätschmer, W.; Lamb, L. D.; Fostiropoulos, K.; Huffman, D. R. Solid C60: a new form of carbon. Nature 1990, 347, 354-358. DOI: 10.1038/347354a0.

2. Haufler, R. E.; Conceicao, J.; Chibante, L. P. F.; Chai, Y.; Byrne, N. E.; Flanagan, S.; Haley, M. M.; O'Brien, S. C.; Pan, C.; Xiao, Z.; Billups, W. E.; Ciufolini, M. A.; Hauge, R. H.; Margrave, J. L.; Wilson, L. J.; Curl, R. F.; Smalley, R. E. Efficient production of $\mathrm{C}_{60}$ (Buckminsterfullerene), $\mathrm{C}_{60} \mathrm{H}_{36}$ and the solvated buckide ion. J. Phys. Chem. 1990, 94, 8634-8636. DOI: $10.1021 / \mathrm{j} 100387 \mathrm{a} 005$.

3. Parker, D. H.; Wurz, P.; Chatterjee, K.; Lykke, K. R.; Hunt, J. E.; Pellin, M. J.; Hemminger, J. C.; Gruen, D. M.; Stock, L. M. High-yield synthesis, separation, and mass-spectrometric characterization of fullerenes $\mathrm{C}_{60}$ to $\mathrm{C}_{266}$. J. Am. Chem. Soc. 1991, 113, 7499-7503. DOI: 10.1021/ja00020a008.

4. Anderson, T. T.; Dyer, P. L.; Dykes, J.W.; Klavins, P.; Anderson, P. E.; Liu, J. Z.; Shelton, R. N.; A plasma arc reactor for fullerene research. Rev. Sci. Instrum. 1994, 65, 3820-3822. DOI: 10.1063/1.1145171.

5. Huczko, A.; Lange, H.; Byszewski, P. Control of fullerene generation through the macroscopic parameters of carbon plasma arc. Fullerene Sci. Technol. 1996, 4, 385-397. DOI: 10.1080/10641229608001558. 
6. Fulcheri, L.; Schwob, Y.; Fabry, F.; Flamant, G.; Chibante, L. F. P.; Laplaze, D. Fullerene production in a 3-phase AC plasma process. Carbon 2000, 38, 797-803. DOI: 10.1016/S00086223(99)00153-0.

7. Huczko, A.; Lange, H.; Byszewski, P.; Poplawska, M.; Starski, A. Fullerene formation in carbon arc: electrode gap dependence and plasma spectroscopy. J. Phys. Chem. A 1997, 101, 1267-1269. DOI: $10.1021 /$ jp962714v.

8. Saïdane, K.; Razafinimanana, M.; Lange, H.; Huczko, A.; Baltas, M.; Gleizes, A.; Meunier, J.-L.; Fullerene synthesis in the graphite electrode arc process: local plasma characteristics and correlation with yield. J. Phys. D: Appl. Phys. 2004, 37, 232-239. DOI: 10.1088/0022-3727/37/2/011.

9. Scrivens, W. A.; Tour, J. M. Synthesis of gram quantities of $\mathrm{C}_{60}$ by plasma discharge in a modified round-bottomed flask. Key parameters for yield optimization and purification. J. Org. Chem. 1992, 57, 6932-6936. DOI: 10.1021/jo00051a047.

10. Weston, A.; Murthy, M. Synthesis of fullerenes: An effort to optimize process parameters. Carbon 1996, 34, 1267-1274. DOI: 10.1016/0008-6223(96)00084-X.

11. Hassan Bhuiyan, Md. K.; Mieno, T. Production characteristics of fullerenes by means of the $\mathrm{J} \times \mathrm{B}$ arc discharge method. Jpn. J. Appl. Phys. 2002, 41, 314-318. DOI: 10.1143/JJAP.41.314.

12. Saito, Y.; Inagaki, M.; Shinohara, H.; Nagashima, H.; Ohkohchi, M.; Ando, Y. Yield of fullerenes generated by contact arc method under He and Ar: dependence on gas pressure. Chem. Phys. Lett. 1992, 200, 643-648. DOI: 10.1016/0009-2614(92)80104-J.

13. Hatakeyama R.; Hirata T.; Ishida H.; Hayashi T.; Sato N. High yield production of $\mathrm{C}_{74}$ using an arc-discharge plasma. Thin Solid Films 1998, 316, 51-55. DOI: 10.1016/S0040-6090(98)00387-3.

14. Afanas'ev, D. V.; Bogdanov, A. A.; Dyuzhev, G. A.; Kruglikov, A. A. Formation of fullerenes in an arc discharge II. Tech. Phys. 1997, 42, 234-237. DOI: 10.1134/1.1258632.

15. Churilov, G. N.; Krätschmer, W.; Osipova, I. V.; Glushenko, G. A.; Vnukova, N. G.; Kolonenko, A. L.; Dudnik, A. I. Synthesis of fullerenes in a high-frequency arc plasma under elevated helium pressure. Carbon 2013, 62, 389-392. DOI: 10.1016/j.carbon.2013.06.022.

16. Churilov, G.; Popov, A.; Vnukova, N.; Dudnik, A.; Samoylova, N.; Glushenko, G. Controlled synthesis of fullerenes and endohedral metallofullerenes in high frequency arc discharge. Fuller. Nanotub. Car. N. 2016, 24, 675-678. DOI: 10.1080/1536383X.2016.1207062. 